\title{
Alfred Marshall, o capitalismo e sua utopia social ${ }^{1}$
}

\author{
Laura Valladão de Mattos ${ }^{2}$
}

\section{Resumo}

Este artigo visa analisar a posição de Marshall em relação ao capitalismo de sua época e às possibilidades de mudança social. Argumenta-se que, apesar de ser um grande defensor do sistema de liberdade econômica, Marshall considerava fundamental sanar o problema da pobreza e da indigência que assolava e degradava física, moral e intelectualmente boa parte da população. Todavia, ao contrário dos socialistas e coletivistas que visavam extinguir as principais instituições vigentes (a concorrência, a propriedade privada, o trabalho assalariado, entre outras), o autor vislumbrava uma sociedade melhor ainda sob a égide dessas instituições capitalistas. Essa situação melhor poderia ser atingida por meio da intervenção do Estado e de mudanças importantes nos valores dos indivíduos - que envolveriam a adoção de uma postura mais nobre e cavalheiresca no seu agir econômico.

Palavras-chave: Alfred Marshall; Capitalismo; Pobreza; Socialismo; Mudança social.

\section{Abstract}

\section{Alfred Marshall, capitalism and his social utopia}

This paper analyses Marshall's view in relation to capitalism and to the possibilities of social change. It is argued that in spite of being an important defender of the system of economic liberty, Marshall thought it was crucial to solve the problems of poverty and indigence that degraded physically, morally and intellectually a great part of the population. He rejected the socialists and collectivists solutions - that aimed at extinguishing the main prevailing institutions, such as competition in the market and private property, and wage-labor; and defended that a better society could be built preserving the key institutions of capitalism. He believed that this better situation could be achieved by prompt intervention of the State, and by important changes in the values of the individuals of society, that involved more nobility and chivalry in their economic action.

Keywords: Alfred Marshall; Capitalism; Poverty; Socialism; Social change.

JEL B13.

\section{Introdução}

A atitude de Marshall é resumida por Joan Robinson como sendo de "[...] defesa satisfeita [complacent] do capitalismo" (Robinson, 1964, p. 1). Segundo

(1) Trabalho recebido em 19 de março de 2010 e aprovado em 21 de setembro de 2010

(2) Professora do Departamento de Economia e do Programa de Estudos Pós-graduados em Economia Política da Pontifícia Universidade Católica de São Paulo (PUC-SP) e bolsista de Produtividade em Pesquisa do CNPq (Conselho Nacional de Desenvolvimento Científico e Tecnológico), São Paulo, SP, Brasil. E-mail: lauramat@uol.com.br. Agradeço o apoio financeiro recebido para o desenvolvimento da pesquisa que resultou no artigo. Agradeço igualmente os preciosos comentários e sugestões de José Eduardo Godoy e Bruno Beltrame e dos pareceristas anônimos da revista. 
ela, "Marshall procura torná-lo aceitável mostrando-o em uma luz agradável" (Idem) ${ }^{3}$.

De fato, é possível encontrar ao longo dos Princípios de Economia e de inúmeros outros textos do autor uma defesa quase sistemática do sistema de 'livreiniciativa e indústria', e críticas bastante contundentes a propostas de transformação radical de sua sociedade. No entanto, argumenta-se que seria inadequado considerá-lo um defensor dogmático do capitalismo liberal. Marshall reconhecia que esse sistema havia gerado enormes problemas sociais, alguns dos quais persistiam, e considerava existir um enorme espaço para o melhoramento social - que exigia muitas vezes limitar a livre-iniciativa. Longe de ser um advogado incondicional do status quo, Marshall almejava uma transformação importante (ainda que gradual) de sua sociedade. É certo que desejava manter alguns dos principais traços do sistema de sua época, no entanto, ansiava por uma sociedade com maior igualdade e justiça social, na qual a totalidade da população (materialmente bem provida e moralmente mais elevada) pudesse, ao contrário do que ocorria então, viver uma vida digna e nobre.

Há, assim, uma tensão no pensamento de Marshall entre o reconhecimento de que existiriam inúmeros problemas (sérios) a serem superados para se chegar a uma situação desejável e a vontade de preservar os principais arranjos institucionais existentes, sem alterá-los de forma significativa.

Este artigo visa explorar essa tensão e discutir a atitude de Marshall em relação ao sistema vigente e às possibilidades de transformação social. Para tal, o presente trabalho está estruturado da seguinte maneira: na seção 1 será analisada sua visão geral sobre o capitalismo e sua evolução histórica, além de serem expostas algumas das razões que fundamentam a defesa (qualificada) que Marshall faz deste. Na seção 2 serão explicitados os principais problemas que acreditava existir em sua época e as críticas lançadas por ele às visões coletivistas e socialistas que se apresentavam como alternativas ao sistema social vigente. $\mathrm{Na}$ seção 3 será apresentada a sociedade (melhor) em direção à qual Marshall considerava que o capitalismo de sua época estaria evoluindo e que deveria ser incentivada pela ação dos homens públicos e da sociedade civil. Para concluir, serão tecidas algumas considerações finais.

(3) Marshall não costuma utilizar o termo capitalismo e sim os termos liberdade econômica (economic liberty) ou liberdade de indústria e iniciativa (freedom of industry and enterprise) para denominar a sua ordem social (Marshall, [1920] (1982), p. 8). No entanto, seguindo vários textos da literatura secundária sobre o autor, o termo capitalismo será utilizado neste trabalho de forma intercambiável com os demais termos adotados por Marshall. 


\section{0 crescimento da 'livre-iniciativa e indústria': a avaliação de Marshall sobre a 'liberdade econômica'}

\subsection{A liberdade econômica: principais elementos}

A visão otimista sobre o capitalismo aparece de forma clara na reconstrução histórica que Marshall apresenta nos Princípios do advento e evolução do sistema de liberdade econômica ${ }^{4}$.

O tipo de sistema que Marshall descreveu (e defendeu) era, como aponta Parsons (1931a, p. 123-124), “[...] caracterizado pela predominância de firmas concorrentes relativamente pequenas, cada uma sob a liderança de um homem de negócios empreendedor e inventivo que, assumindo o risco, faz experiências com várias combinações de fatores produtivos." Ou seja, o capitalismo competitivo que ele representa teoricamente, mais adiante nos Principios, através das hipóteses de concorrência perfeita ${ }^{5}$. A forma predominante de relações de trabalho nessas firmas era a assalariada, na qual "[...] o planejamento e organização dos negócios, sua administração e riscos são assumidos por um conjunto de pessoas, enquanto o trabalho manual requerido é feito por trabalhadores contratados [hired labour]" (Marshall, [1920] (1982), p. 617).

No entanto, não foram essas características econômicas que Marshall enfatizou na sua caracterização do sistema de liberdade econômica. Ele destacou, ao contrário, alguns traços de caráter dos indivíduos que compunham a sociedade moderna para distingui-la das demais - e os traços que escolheu selecionar não foram aqueles em geral enfatizados por seus contemporâneos, a saber, o egoísmo e a competição. Marshall admitia que um aumento da competição e do egoísmo acompanhou o surgimento e consolidação desse sistema, mas ele não os considerava elementos constitutivos dessa ordem e recusava-se a defini-la com base nessas características (Ibidem, p. 8). Na sua opinião, "[...] a deliberação e não o egoísmo que é a característica da era moderna.” (Ibidem, p. 5). Os homens de sua época caracterizar-se-iam por:

(4) Marshall inicia os seus Principios com uma breve caracterização e um rápido histórico do sistema baseado na livre-iniciativa que passou a organizar a vida social a partir do final do século XVIII. Nas primeiras versões dos Principios, esse capítulo histórico era bem mais extenso, no entanto, posteriormente Marshall resolveu organizar a maior parte do conteúdo no apêndice A dos Principios denominado: "The growth of free industry and enterprise" (Keynes, [1925] 1966, p. 45-46). Parte da sua avaliação sobre o capitalismo aparece neste material histórico, no entanto, a sua visão sobre a sua sociedade e as possibilidades de mudança revela-se também, de forma mais esparsa, ao longo de outras passagens dos Princípios e em artigos e textos de Marshall.

(5) Segundo Parsons (1931a), a maior parte das hipóteses de concorrência adotadas por Marshall era, para ele, "[...] muito mais do que um conjunto de abstrações metodológicas; representavam, ao contrário, em grande medida, descrições reais do sistema de livre-iniciativa [...].” (p. 127). Shove (1942) também ressalta que os Principios de Marshall referiam-se basicamente a um contexto de capitalismo individualista: "Era uma sutil e magistral análise das principais forças em ação na determinação dos preços relativos quando o capitalismo individualista já tinha avançado bastante [got well into his stride] e tinha transformado as técnicas industriais, mas ainda retinha muito da sua força expansionista inicial [...]” (p. 327). 
[...] uma certa independência e hábito de cada um escolher o seu próprio roteiro, uma confiança em si mesmo; uma deliberação e mesmo uma presteza de escolha e julgamento e um hábito de projetar o futuro e modelar cada um o seu programa tendo em vista objetivos distantes (ibidem, p. 4).

Assim, Marshall seleciona como a marca distintiva desse sistema vis-à-vis os anteriores a atitude racional e empreendedora dos indivíduos que o constituem. E o interessante é que ele associa a predominância dessas características às instituições econômicas em $\operatorname{voga}^{6}$. No seu entender, atividades econômicas exercidas pelos homens teriam um impacto fundamental sobre a natureza humana:

[o] caráter do homem tem sido moldado por seu trabalho diário, e pelos recursos materiais que obtém por meio deste, mais do que por qualquer outra influência, excetuados os seus ideais religiosos (Marshall, [1920] (1982), p. 1).

Justamente por moldarem o caráter, os desejos e as necessidades dos homens é que as atividades econômicas assumiram um papel de destaque na análise de Marshall. O seu principal objetivo ao estudar Economia foi o de encontrar meios de aprimorar o caráter dos homens através da melhoria na sua condição material e de trabalho ${ }^{7}$. Assim, o grande interesse que ele demonstrou ter por esta ciência derivou-se, acima de tudo, do fato de esta ser, no seu entendimento, além de um estudo sobre a riqueza, "[...] uma parte do estudo do homem" (Ibidem).

E, como aponta Parsons, boa parte da simpatia que Marshall nutria pelo sistema de liberdade econômica decorria de acreditar que, além de este gerar um enorme crescimento da riqueza, cumpriria igualmente o importante papel de aprimorar os homens. De uma forma geral, as atividades e instituições capitalistas teriam, segundo Marshall, engendrado nos homens várias características

(6) Shove (1942) afirma que Marshall "“...] estava bastante consciente de que a liberdade de competição [...] era de origem bastante recente e que existiam muitas partes do mundo que ela estava apenas começando a atingir" (p. 308). O autor afirma igualmente que Marshall nunca perdeu de vista o contexto histórico no qual se dava a sua análise do sistema industrial (Idem).

(7) Como coloca Raffaelli (2006), para Marshall, “[...] os assuntos mundanos da produção e distribuição valem a pena ser estudados basicamente por seu impacto sobre o caráter humano" (p. 488). No seu entender, "[...] a principal importância da riqueza material está no fato de, quando sabiamente utilizada, aumentar a saúde e a força física e psicológica da raça humana" (Marshall apud Caldari, 2004, p. 534). Como enfatiza Coats (1990): "Para Marshall, a missão do economista era, em si mesma, um empreendimento ético. O seu propósito não era meramente aliviar a pobreza e o sofrimento, mas ajudar a elevar a 'qualidade da vida humana' [...]" (p. 158). Marshall não se interessava apenas em analisar o problema econômico de forma estática. Ele visava melhorar o homem, suas faculdades e seus desejos através de mudanças nas condições de vida: "[...] o problema econômico era visto por Marshall não como o meio de responder a necessidades/desejos [wants] humanos fixos, mas de levar à emergência de traços de caráter eticamente preferíveis que teriam como acompanhamento necessidades/desejos [wants] adequados" (Whitaker, 1977, p. 17). 
desejáveis, tais como energia de caráter, racionalidade, iniciativa, frugalidade, empenho e condutas honradas (Parsons, 1931a, p. 107, 127-128).

O capitão de indústria, o homem de negócios de visão, incorporaria todas essas características e pode ser visto como uma espécie de herói de Marshall ${ }^{9}$. Ele é representado como um homem forte, energético, corajoso, inovador, racional e ao mesmo tempo intuitivo, que quebraria a rotina e arriscaria a sua riqueza em novos experimentos (Reisman, 1987, p. 94-95; Marshall, [1907] 1966) ${ }^{10}$. Da sua ação deliberada e criativa teriam resultado, no entender de Marshall, o dinamismo do sistema, o progresso tecnológico e o crescimento da riqueza; dela teriam decorrido, igualmente, alguns dos graves problemas observados nos primórdios do capitalismo. Poucos homens teriam essas qualidades associadas ao capitão de indústria, no entanto, com a adição de uma pitada de cavalheirismo e nobreza ao seu agir econômico, eles desempenhariam papel crucial na continuidade do crescimento econômico e na construção de uma sociedade melhor ${ }^{11}$.

\subsection{A história do crescimento da 'liberdade econômica': O melhoramento humano e social}

Embora nutrisse uma óbvia simpatia pelo sistema de liberdade econômica, Marshall ([1920] 1982), não negava que a emergência deste gerou enormes sofrimentos sociais. Nesse período, "[...] a livre competição, ou a liberdade de iniciativa e indústria, foi deixada livre para percorrer, como um enorme monstro indomado, o seu curso desregrado [...]” (p. 9). Essa nova ordem social teria

(8) Para Parsons (1931a), “[...] de uma forma geral, Marshall via o campo dos negócios como sendo a principal oportunidade para o exercício daquilo que ele considerava as características nobres do caráter humano. A riqueza que acompanhava o processo não era a meta, mas um subproduto [...]” (p. 115). Na opinião do autor, Marshall provavelmente defenderia este sistema ainda que fosse menos eficiente que outros tal era a sua admiração pelo tipo de caráter que ele gerava nos homens (Ibidem, p. 125).

(9) G. S. sugere que Marshall “[...] substituiu a máquina calculadora proverbial por um novo 'homem econômico' - 'audacioso', com ‘visão de futuro', 'alerta', 'engenhoso', tendo uma marcada semelhança com os capitães de indústria com os quais as propagandas de economia de guerra e os filmes norte-americanos nos tornaram familiares, e quase tão diferentes da vida real quanto estes são.” (G. S. apud Maloney, 1990, p. 179). Maloney aponta a importância dessa figura (estereotipada) no pensamento marshalliano: “[...] Marshall precisava do homem de negócios como um arquétipo do que demarcava a sociedade industrial moderna de outros tempos e lugares [...]" (Maloney, 1990, p. 196, ênfase no original).

(10) Estes líderes naturais teriam a capacidade de "[...] ir direto ao cerne dos problemas práticos [...], de ver quase instintivamente as proporções inatas das coisas, de conceber políticas sábias e de longo alcance, e executá-las com calma e resolução" (Marshall apud Pesciarelli, 2006, p. 344). Mas, como aponta Pesciarelli (2006), nem todos os homens teriam essa descrição: "Este seria um conjunto de faculdades - como dons naturais raros - que não podem ser aprendidos" (p. 344).

(11) Comentando a obra de Marshall, Whitaker (1977) afirma: “[...] era sobre o empresário inovador, com antevisão, pioneiro [...] que a principal responsabilidade pelo progresso econômico e moral do mundo passou a ser colocada [a partir de 1890].” (p. 191). Keynes ([1926] 1984) questiona a confiança depositada no capitão de indústria, "[...] o mestre individualista que nos serve ao servir-se a si mesmo, exatamente como faz qualquer outro artista” (p. 119). Para ele, este “[...] está se transformando num ídolo caído. Temos cada vez mais dúvidas sobre se é ele que nos conduzirá ao Paraíso pela mão" (Ibidem). 
destruído as tradições e os costumes que serviam de proteção aos pobres e fracos e, simultaneamente, teria dado poder a hábeis, mas ainda incultos, homens de negócios que o utilizaram de forma egoísta: “[...] O empregador capitalista, sem preparo para os seus novos deveres, ficou tentado a subordinar o bem-estar de seus trabalhadores a seu próprio desejo de ganho [...]" (Ibidem, p. 621).

Marshall apresenta algumas justificativas para a falta de sensibilidade desses primeiros capitalistas para com os seus trabalhadores:

A nova raça de empreendedores predominantemente constituída por aqueles que fizeram suas próprias fortunas, homens fortes e com iniciativa [...] tinha a tendência a considerar que o pobre e o fraco deveriam ser responsabilizados e não lastimados [pitied] por suas desgraças [...] (Ibidem, p. 620).

Assim clamaram por liberdade econômica, e por serem mais fortes impuseram a sua vontade ${ }^{12}$. Teria havido, assim, um abuso generalizado por parte dessa classe, que "[...] levou a males por todos os lados; tornou mães inadequadas para suas funções; massacrou crianças com sobretrabalho e doenças; e em vários lugares degradou a raça" (Ibidem, p. 9).

No entanto, Marshall, apesar de não isentá-lo de culpa, tampouco responsabiliza exclusivamente a ação desse 'monstro indomado' pela situação lamentável que veio a prevalecer no começo do século XIX. Nem todos os problemas sociais teriam sido devidos à "[...] erupção da competição descontrolada" (Ibidem, p. 619). Ele cita a perda das colônias, a guerra com a França e uma sucessão de péssimas colheitas, e especialmente a Lei dos Pobres que caminhava em direção contrária à liberdade econômica - como corresponsáveis pela deterioração observada na qualidade de vida da população (Ibidem) $)^{13}$. O dano não teria sido causado unicamente pela predominância desta nova ordem social, "[...] seus males tendo sido intensificados e suas influências benéficas retardadas por infortúnios externos" (Ibidem, p. 619). Marshall inclusive criticou vários economistas da época por se posicionarem contra a competição, pois acreditava que muito da ignorância e sofrimento atribuídos a essa instituição eram na verdade resultados "[...] ou da tirania e opressão de épocas passadas ou da má compreensão e do mau gerenciamento da liberdade econômica." (Ibidem, p. 10).

De qualquer forma, Marshall admite que o nascimento do capitalismo foi acompanhado por um aumento dos problemas sociais e por péssimas condições de

(12) “[...] Eles glorificavam a individualidade de caráter e não tinham pressa alguma em encontrar substitutos modernos para os vínculos sociais e industriais que uniam os homens em tempos passados" (Marshall, [1920] (1982), p. 620).

(13) Sobre a Lei dos Pobres, Marshall ([1920] 1982), afirma: “[...] a irresponsabilidade bemintencionada da lei dos pobres fez ainda mais para reduzir a energia física e moral dos ingleses do que a irresponsabilidade desalmada [hard-hearted] da disciplina manufatureira [...]” (p. 9). 
trabalho, de moradia e de vida - circunstâncias que atuaram durante algum tempo no sentido de degradar o caráter de boa parte da população. Contudo, não considerava esses aspectos perversos que historicamente estiveram associados à sua emergência como inerentes ao sistema de livre-iniciativa e indústria. Ele inclusive esforça-se por mostrar que muitos dos problemas foram sendo paulatinamente corrigidos com a evolução do sistema e com o gradual amadurecimento moral e intelectual da sociedade.

Como ressaltam Collini et al. (1983), ao escolher a deliberação, e não o egoísmo, como sendo a característica central do sistema de liberdade econômica, Marshall "[...] abria espaço para cooperação deliberada e para não egoísmo deliberado [deliberate unselfishness] [...]" (p. 314-315). Apesar de a deliberação, a previsão e as escolhas racionais dos indivíduos visarem frequentemente, em sua sociedade, a finalidades egoístas, Marshall ([1920] 1982), frisa que estas estariam sendo crescentemente utilizadas de forma cooperativa (p. 4) ${ }^{14}$.

No cômputo geral, após um século de existência, na opinião de Marshall, o sistema de liberdade econômica teria engendrado homens melhores do que aqueles existentes em ordens sociais passadas. Havia, sim, mais egoísmo na sua época do que em períodos anteriores, mas isso decorreria da ampliação do escopo da escolha, e não do fato de os homens terem se tornado moralmente piores ou mais individualistas. Para Marshall, em sociedades primitivas, as regras e os costumes norteavam grande parte da vida dos indivíduos, deixando pouco espaço para a escolha (seja egoísta ou altruísta). E os registros históricos e o conhecimento existente sobre os povos 'atrasados' não indicavam que esses povos seriam mais capazes do que os ingleses de sua época de se sacrificarem pelo benefício dos outros nos casos em que os costumes e leis permitiam que escolhessem livremente (Ibidem, p. 5-6). Pelo contrário, ele não tinha dúvidas de que o homem inglês de sua época era de uma forma geral moralmente mais elevado do que os demais povos ${ }^{15}$. Um indício disso seria o fato de o enorme aumento das oportunidades para a corrupção e desonestidade não ter sido

(14) Nem sempre essas associações e combinações beneficiavam a sociedade. Por vezes, grupos que agiam de forma cooperativa visavam a benefícios próprios e agiam em detrimento dos interesses de toda a sociedade, por exemplo, algumas organizações sindicais.

(15) Parsons (1931a) é bastante crítico em relação à história econômica desenvolvida por Marshall, que era "[...] essencialmente a história do desenvolvimento da livre-iniciativa" (p. 130). Para esse autor, Marshall apresenta uma visão unilinear de evolução social, as outras ordens sociais seriam apenas estágios desse desenvolvimento em relação ao sistema da época (Parsons, 1931b, p. 331): "Os ingleses muitas vezes ridicularizaram Hegel por supor que a evolução da Weltgeist ocorreu unicamente com o propósito de produzir o Estado Prussiano do começo do século dezenove. E, no entanto, Marshall, bom inglês que era, supôs que todo o processo leva à produção do artesão e do homem de negócios inglês da parte final do mesmo século. [...]" (Ibidem, p. 335). Esse paralelo de Parsons entre Marshall e Hegel parece pertinente, uma vez que, como aponta Raffaelli (2006), Marshall admitiu que o apêndice A - que conta a história do triunfo da livre-iniciativa - "não pertence à história econômica propriamente dita, mas a um gênero de história conceitual [conceptualized history] a la Hegel [...]" (p. 493). 
acompanhado por um aumento proporcional na ocorrência destas ações (Ibidem, p. 6). Marshall aponta também que houve um aumento significativo da confiabilidade (trust) dos homens e argumenta que o altruísmo na relação com a família e com os estranhos era maior na era moderna do que anteriormente (Ibidem, p. 5-6).

Ao longo do século XIX, ter-se-ia observado um aumento da educação geral, uma elevação da demanda por trabalho qualificado e uma paulatina substituição do trabalhador não qualificado por máquinas na execução dos trabalhos mais pesados e repetitivos. Os homens foram assim libertados de muitas das atividades mais rudes e degradantes (Marshall, [1920] (1982), p. 3, 596). A elevação de demanda por trabalho mais qualificado levou a classe dos artesãos a crescer rapidamente e superar em números aquela de trabalhadores inteiramente não qualificados ${ }^{16}$. Isso teria trazido muitos benefícios uma vez que essas atividades ao exigirem dos homens o exercício de várias habilidades sociais, intelectuais e morais acabavam por aprimorá-los e melhorar a sua condição de vida.

Assim, uma proporção crescente dos homens passou a exercer ocupações com as características do que Marshall denomina atividades de gentlemen, que "[...] eleva o caráter e educa as faculdades, direta ou indiretamente, ao treiná-los ou por associação, nas horas de negócios (business) ou nas horas de lazer [...]" (Marshall, [1873] (1966), p. 104). E Marshall ([1920] 1982), constata que "[u]ma grande parte dos artesãos [...] já leva uma vida mais refinada e nobre do que a maior parte da classe mais elevada [upper class] levava há um século" (p. 3).

Esse aumento na educação do povo e os avanços nas atividades exercidas, associados à generalização do acesso à informação, à ampliação do direito ao voto e à organização de sindicatos de trabalhadores, teriam levado a um aprimoramento moral na população e a uma maior preocupação e atenção com as condições sociais e de trabalho. A opinião pública passou a mobilizar-se em relação a essas questões e a pressionar crescentemente, seja através do governo (e da legislação),

(16) “[...] dá para estimar aproximadamente que aqueles que são capazes somente de trabalho não qualificado constituem perto de um quarto da população. E aqueles que, embora talhados para trabalhos qualificados de tipo mais simples não são adaptados para trabalho altamente qualificado, nem são capazes de agir de forma sábia e rápida em posições de responsabilidade, constituem um outro quarto. Se estimativa similar tivesse sido feita na Inglaterra há um século, as proporções teriam sido bem diferentes: ver-se-ia que mais da metade seria inadequada para exercer qualquer trabalho qualificado além da rotina comum da agricultura, e talvez menos do que uma sexta parte da população seria talhada para trabalho altamente qualificado ou de alta responsabilidade" (Marshall, [1920] (1982), p. 596). Ele ressalta também que mesmo as atividades desempenhadas pelos trabalhadores não qualificados exigiriam uma qualificação e disciplina maiores do que a exigida anteriormente: “[...] o chamado trabalhador 'não qualificado' hoje tem que frequentemente lidar com instrumentos tão sutis e tão caros que não teriam sido com segurança confiados a um trabalhador comum inglês de um século atrás, ou confiados hoje a qualquer pessoa em alguns países atrasados" (Ibidem). 
seja manifestando-se diretamente, por melhorias ${ }^{17}$. Marshall ([1890] 1966), ressalta a relevância desse fato ao apontar "[...] o aumento da esfera na qual a opinião pública se manifesta, e na força com a qual ela influencia diretamente os assuntos econômicos" (p. 286) como uma das mudanças econômicas mais importantes de sua época.

Marshall ([1920] 1982), faz ainda questão de frisar o avanço ocorrido na qualidade dos gastos da população em geral - que passou a ser mais altruísta -, mudança que teria favorecido basicamente os pobres ${ }^{18}$ : "O país que é o berço da competição moderna devota uma parcela maior de sua renda do que qualquer outro para usos caritativos [...]" (p. 5).

Assim, o exercício desregrado da livre-iniciativa foi sendo limitado através da pressão da opinião pública, do aumento da intervenção do Estado e da ação consciente dos homens de negócios, e outros fins sociais além do aumento da riqueza começaram a ser reconhecidos e buscados (Ibidem, p. 621). Como conseqüência, muitos abusos e problemas foram corrigidos e as condições sociais e de trabalho melhoraram de forma significativa ao longo do século XIX (Ibidem, p. 620). O 'monstro indomado' teria sido, pelo menos em parte, 'domesticado'.

Dessa forma, paradoxalmente, o mesmo processo de consolidação do capitalismo, que colocou em marcha a enorme e generalizada busca por riqueza, teria engendrado a elevação moral da sociedade e a valorização de outras finalidades ${ }^{19}$. E esse melhoramento moral observado nos homens teria sido, segundo Marshall, fundamental para o desenvolvimento econômico e social

(17) Por opinião pública quer dizer a opinião do homem médio que não está diretamente envolvido nas questões em voga (Marshall, [1890] 1966, p. 287). A opinião pública influencia a ação dos indivíduos uma vez que, para Marshall, “[...] o desejo do homem por aprovação de sua própria consciência e pela estima dos outros é uma força econômica de primeira ordem de importância [...]" (Ibidem, p. 285). Whitaker (1977, p. 191) aponta que, por volta de 1890, Marshall passa a dar maior ênfase ao papel regulador da opinião pública como complemento ao senso de dever.

(18) Marshall (1907) afirma ter havido uma modificação nos gastos públicos, que refletem essas mudanças de valores na sociedade: “[...] o principal gasto de dinheiro público [...] foi para o benefício de mulheres e crianças [...] a nossa era reverteu as velhas regras de que pobres pagavam uma percentagem maior de suas rendas em impostos do que os ricos, e que o Tesouro era mais generoso em fornecer sinecuras para ricos, do que em diminuir a ignorância, doença e sofrimento dos pobres." (Idem). Para ele, "[...] o uso que tem sido feito do aumento de riqueza não é, no conjunto, sórdido ou egoísta. [...]” (p. 327-328).

(19) Como coloca adequadamente Reisman (1987): "Marshall [...] adotou a visão de que o capitalismo aquisitivo deveria ser congratulado por ter crescentemente gerado precisamente aquele fundo de valores não aquisitivos e não competitivos [...].” (p. 36). Whitaker, por sua vez, questiona a ligação que Marshall estabelece entre o sistema de liberdade econômica e o crescimento das qualidades morais nos homens: "As bases para a crença veemente na livre-iniciativa em desenvolver o caráter humano permanecem vagas. As características de antecipação do futuro [far-sightedness], racionalidade, iniciativa, energia, autocontrole, autodesenvolvimento e frugalidade teriam uma tendência óbvia de florescer em um ambiente competitivo [...]. No entanto, a liberdade [econômica] teria menos probabilidade de promover as virtudes altruístas sociais [...]” (Whitaker, 1977, p. 181). 
observado em sua época ${ }^{20}$. O elemento moral e de honradez nos relacionamentos que se encontrava praticamente ausente quando do advento do sistema de liberdade econômica passou a existir em maior quantidade e poderia, segundo Marshall, crescer ainda mais - e, como será visto, esse aprimoramento geral constitui um elemento cardinal da sua utopia social.

\section{Reformando o capitalismo: A questão da pobreza e o caminho para uma sociedade melhor}

O panorama geral traçado por Marshall sobre o capitalismo e sua evolução de fato condiz bastante com a afirmação de Joan Robinson de que ele procura apresentar esse sistema sob uma luz agradável. O capitalismo teria conseguido, além de aumentar tremendamente a riqueza, proporcionar circunstâncias e atividades que permitiram desenvolver características intelectuais e morais consideráveis nos homens.

Todavia, argumenta-se que Marshall estava longe de considerar o sistema de sua época justo ou satisfatório. Ele tinha ciência de que vários problemas sociais persistiam e que o capitalismo, apesar de ter trazido vários benefícios, não teria conseguido resolver a contento o problema da pobreza e da degradação física, intelectual e moral de um grande número de pessoas. No que concerne a esses indivíduos, o cenário vigente ainda era lúgubre e sombrio, e foi justamente essa situação de desigualdade, injustiça e pobreza que o levou a dedicar-se ao estudo da Economia Política $^{21}$. Grande parte de seus esforços foi destinada a tentar melhorar as condições de vida e de trabalho dessas pessoas e, por meio disso, aprimorar as próprias pessoas $^{22}$. Já na sua maturidade, ao fazer uma avaliação geral das suas contribuições, ele afirma:

(20) Parsons (1931a), afirma que “[...] a livre-iniciativa de Marshall não é de forma nenhuma [...] um estado hobbesiano de natureza. É em todo lado ligada de forma próxima por normas éticas. De novo e de novo ele [Marshall] reitera que somente o grande melhoramento no caráter e na moralidade ocorrido nos tempos recentes tornou o desenvolvimento econômico possível" (p. 125).

(21) Ele relata a sua trajetória rumo à Economia da seguinte forma: "Da metafísica eu fui para a ética, e achei que justificar a sociedade existente não era fácil [...] Li, então, os Princípios de Economia Política de Mill, e fiquei muito excitado com o livro [...] Então, nas minhas férias eu visitei os quarteirões mais pobres de várias cidades e andei em uma rua após a outra, olhando para as caras das pessoas mais pobres. Em seguida, eu resolvi fazer o estudo mais completo possível de Economia Política" (Marshall apud Keynes, [1925] 1966, p. 10).

(22) Como coloca Keynes, "a solução dos problemas econômicos era para Marshall [...] a pré-condição para o exercício das faculdades mais elevadas [...]" (Keynes, [1925] 1966, p. 9). Ao assumir a cadeira de Economia Política em Cambridge, Marshall revela o que entendia ser sua missão: “[...] aumentar o número daqueles que Cambridge, a grande mãe dos homens fortes, manda para o mundo com cabeças ponderadas, mas corações quentes, dispostos a dar pelo menos parte de seus melhores poderes para combater o sofrimento que os circunda, resolvidos a não ficarem satisfeitos enquanto não tiverem feito tudo em seu alcance para descobrir o quanto é possível abrir, para todos, os meios materiais de uma vida nobre e refinada" (Marshall, 1885, p. 174). 
Eu me devotei nos últimos vinte e cinco anos ao problema da pobreza e [...] muito pouco do meu trabalho tem sido devotado a qualquer investigação que não tenha relação com isso (Marshall apud Viner, 1941, p. 228).

\subsection{Pobreza e degradação humana: A situação dos trabalhadores não qualificados e do Residuum}

Marshall via que uma parte significativa da população (apesar de bem menor do que anteriormente) - a dos trabalhadores não qualificados - submetia-se a condições de trabalho, moradia e lazer muito precárias. Observava, igualmente, que outra parcela da população (denominada de Residuum) situava-se à margem do desenvolvimento promovido pelo capitalismo, sendo incapaz de se inserir no mercado de trabalho e, portanto, de garantir a sua própria subsistência e a dos seus filhos.

No que tange aos trabalhadores não qualificados, o trabalho que exerciam não partilhava, de forma nenhuma, a natureza da atividade de gentlemen. $\mathrm{O}$ trabalho duro, prolongado e repetitivo, associado à baixa remuneração paga por esse tipo de atividade - que acarretava condições de habitação e lazer muito ruins - em vez de fortalecer e completar as esferas moral, mental e física do homem, as massacrava.

A imagem que Marshall apresenta é a de "[...] vastas massas de homens que, após longas horas de trabalho duro e não intelectual, têm o costume de voltar para as suas casas estreitas com os corpos exaustos e com as mentes entediadas [dull] e letárgicas [...]" (Marshall, [1873] (1966), p. 105). Além de afetar a sua saúde e seu intelecto, esse tipo de atividade deterioraria também os seus desejos e o seu consumo, uma vez que Marshall associa essa condição de exaustão e consequente apatia a uma degradação moral e à busca de prazeres pouco elevados: "[...] se o seu trabalho foi brutal e, portanto, o seu cérebro está entorpecido, ele tem a tendência de procurar [...] somente os prazeres mais grosseiros - bebida, gracejos ignóbeis e barulho [...]" (Ibidem, p. 107).

Haveria sob essas condições um embrutecimento dos homens. Com o corpo exaurido pelo trabalho, o trabalhador não teria a menor condição de aprender, ou de ao menos se interessar por coisas mais elevadas. Segundo Marshall, ([1873] 1966), “[...] nós quase não nos damos conta de quão sutil, totalizante e poderoso pode ser o efeito do trabalho corporal em apequenar o crescimento do homem" (p. 105-106).

Assim, para uma boa parte da população, as atividades exercidas teriam um efeito mutilador sobre o seu o intelecto, sua moral e sua vida interior: 
[...] existe um vasto número de pessoas tanto nas cidades como no campo que são criadas com comida, vestimenta e espaço em moradias insuficientes; cuja educação é interrompida cedo para que possam trabalhar em troca de salários; e que, a partir de então, se engajam durante longas horas em trabalhos exaustivos com corpos mal nutridos, e que não têm, portanto, qualquer possibilidade de desenvolver as suas faculdades mentais mais elevadas (Marshall, [1920] (1982), p. 2$)^{23}$.

A situação era, no entender de Marshall, ainda mais alarmante quando se tratava do Residuum - pessoas que, por insuficiências físicas, morais ou intelectuais são incapazes de obter um salário em troca de seu trabalho (Ibidem, p. 594).

Apesar de Marshall ter a firme convicção de que o sistema de liberdade econômica era o "[...] o melhor tanto do ponto de vista moral como material para aqueles em uma condição razoavelmente boa de saúde da mente e do corpo." (Ibidem), ele reconhecia que isso não valia para Residuum, que não conseguia se inserir no sistema ou desfrutar de suas vantagens (Ibidem). Esses indivíduos levavam uma vida degradada em todos os sentidos, e Marshall imputava essa condição odiosa de falta de saúde mental, física e moral basicamente à própria pobreza: "[...] a destruição do pobre é a sua pobreza, e o estudo das causas da pobreza é o estudo das causas da degeneração de uma grande parte da humanidade" (Ibidem, p. 2).

Seria imperativo romper com o círculo vicioso de a pobreza causar degradação que, por sua vez, causava mais pobreza - situação esta que se perpetuaria através das gerações. Todavia, estava claro para Marshall que o sistema de liberdade econômica, apesar de ter tido impactos excelentes em outros aspectos da vida social, não estaria dando conta de equacionar adequadamente esse problema.

\subsection{Transformando o sistema: $\mathrm{A}$ rejeição às alternativas socialistas $\mathrm{e}$ coletivistas}

A questão da pobreza e da degradação moral que a acompanharia era, como argumentado, central ao pensamento de Marshall. No entanto, apesar de admitir que até o momento o capitalismo não tinha sido capaz de resolver esse problema, ele rejeitou de forma peremptória as saídas revolucionárias, socialistas e coletivistas, que se apresentavam na época como soluções para as mazelas sociais.

Embora atraído pelos objetivos de melhoria social apresentados pelos socialistas, "[...] que devem despertar a simpatia de qualquer um que tenha um

(23) No mesmo sentido afirma: "[...] Sobrecarregadas com trabalho [overworked] e educadas de forma insuficiente [undertaught], preocupadas e cansadas, sem sossego e sem lazer, elas não têm nenhuma chance de aproveitar ao máximo as suas faculdades mentais” (Marshall, [1920] (1982), p. 2). 
coração" (Marshall apud Keynes, [1925] (1966), p. 16) ${ }^{24}$, ele rechaçou os meios apresentados para atingi-los. No seu entender, o socialismo seria "[...] um movimento para tirar a responsabilidade pela vida do homem e por seu trabalho, tanto quanto possível, dos seus ombros e colocá-los nos ombros do Estado [...]" (Marshall apud Reisman, 1987, p. 122) e a implementação de suas propostas representaria enormes riscos para a sociedade ${ }^{25}$.

As críticas apresentadas a estas alternativas sociais foram de várias ordens $^{26}$. Marshall deixa claro que considerava insensatas e inadequadas as propostas socialistas de extinguir a concorrência e implantar arranjos que exigiriam para o seu bom funcionamento altas doses de altruísmo ou de qualidades morais, uma vez que o homem de sua época não havia alcançado tal nível de perfeição moral (Marshall, [1907] (1966), p. 341). No seu entender, "[...] na condução responsável dos assuntos, é pior que loucura ignorar as imperfeições que ainda se prendem à natureza humana" (Marshall, [1920] (1982), p. 7). Dado o nível de desenvolvimento moral e intelectual de seus contemporâneos, a concorrência no mercado mostrava-se útil. Portanto, antes de pensar em extinguir ou restringi-la seria necessário ter a certeza de que "[...] as restrições à competição não seriam mais antissociais no seu funcionamento do que o funcionamento da própria competição" (Marshall, [1920] (1982), p. 8).

Outra crítica importante dizia respeito ao perigo de ocorrer uma estagnação no que concerne às inovações tecnológicas. Como mencionado, o capitão de indústria - aquele empresário que assume riscos e abre um negócio por sua própria conta - é uma figura central ao pensamento de Marshall. É ele que inova, é ele que arrisca, é ele que ao buscar seu próprio ganho beneficia toda a sociedade. É certo que nem todos os homens de negócio tinham essa descrição. Muitos aguardavam e imitavam as invenções desses empreendedores, mas a existência de empresários inovadores seria, no entender de Marshall, fundamental para o dinamismo da economia. E era justamente esse elemento que, na sua avaliação, correria enorme risco com o coletivismo ou o socialismo.

(24) Nesta mesma linha, sua esposa Mary relata: "Uma vez ele [Alfred] disse que qualquer um que não seja um socialista em seu coração [socialist at heart] é em minha opinião menos que humano" (Marshall apud Tullberg, 2006, p. 517).

(25) Groenewegen (1995) mostra que a posição de Marshall em relação ao socialismo alterou-se bastante, tornando-se mais crítica com o passar do tempo: "Por uma década mais ou menos, durante a impetuosidade da juventude, o seu interesse [no socialismo] foi relativamente ativo; depois se tornou gradualmente mais crítico e, ocasionalmente, até hostil, parcialmente por conta dos crescentes problemas teóricos que Marshall identificava no socialismo, e parcialmente porque crenças anteriores no socialismo não mais se ajustavam aos seus ideais sociais e políticos" (p. 570). Para uma descrição detalhada da evolução do pensamento de Marshall sobre o tema, ver Groenewegen (1995, p. 571-617).

(26) Para uma análise bastante detalhada do que Marshall entendia por socialistas e das principais críticas direcionadas por ele a essas alternativas, ver Reisman (1987, p. 121-127). 
Para cumprir seu papel de inovador, o homem de negócios requereria recursos à sua disposição a serem utilizados com tempo e liberdade, no entanto, não encontraria essas condições nas empresas administradas pelo Estado ou mesmo, apesar de em menor grau, nas grandes corporações privadas ${ }^{27}$. Faltaria espaço, liberdade e incentivo para pôr em prática as suas ideias:

[...] se ele é um servo de uma burocracia, ele não pode ter certeza de liberdade [...] uma mudança na administração, ou impaciência diante do fracasso em achar a verdadeira rota para o progresso na primeira tentativa pode levar a que seja retirada; e suas correntes batem, mesmo quando não apertam muito (Marshall, [1907] (1966), p. 333) 28 .

Em grandes firmas onde existe uma divisão entre a propriedade e o gerenciamento do negócio, haveria uma tendência a manter-se na rotina e prevaleceria uma aversão a inovações. Existiria pouco estímulo para arriscar: se a inovação rende frutos, a maior parte dos ganhos não fica com quem a introduziu; e, se fracassa, a maior parte do ônus recai sobre esse indivíduo ${ }^{29}$. E, no entender de Marshall, os esquemas de incentivo concebíveis dentro dessas grandes organizações (promoções, prêmios, distinções, etc.) ainda não teriam dado conta de resolver o problema da criação e inventividade:

[...] não se achou um substituto razoavelmente bom, e nem parece que seja provável que se ache, para o ar fresco que um homem forte com vontade cavalheiresca por liderança traz aos pulmões quando ele sai e estabelece um experimento de negócio por sua própria conta e risco (Marshall, [1907] (1966), p. 333).

Além disso, como aponta Parsons, o efeito dessas grandes burocracias e de sociedades com decisões coletivas seria, segundo Marshall, deletério sobre o caráter humano. A elas ele associa o surgimento de várias características consideradas indesejáveis nos homens, como “[...] a apatia, a estagnação letárgica, a escravidão aos costumes, a falta de ambição [...]”" (Parsons, 1931a, p. 107).

A questão do risco à liberdade e à diversidade representado pelo coletivismo também aparece como uma crítica crucial. Nesse sentido, Marshall afirma que "[...] é mais importante lidar com as verdades expostas no Liberty de Mill do que nos seus Essays on Socialism" (Marshall apud Tullberg, 2006, p. 520).

(27) Para os riscos que Marshall associava ao crescimento do peso das joint ventures, ver Pesciarelli (2006, p. 350-351).

(28) Para Marshall (1890), “[...] apesar de os administradores de uma companhia possivelmente terem alguma liberdade para experimentar em questões de detalhes [...] no que concerne a grandes questões, a liberdade para experimentação só existe para aqueles que são responsáveis pelo empreendimento [...] (p. 280).

(29) Essa questão do risco e da inovação e do benefício que traria para a sociedade parecia ser minimizada ou ignorada pelos reformadores sociais: "Eles parecem pensar demais na competição como a exploração do trabalho pelo capital, do pobre pelo rico, e insuficientemente nela como uma constante experimentação por parte dos homens mais capazes para suas diversas tarefas, cada um tentando descobrir um novo meio pelo qual atingir algum fim importante" (Marshall, [1890] 1966, p. 283). 
Em vários sentidos, portanto, as propostas socialistas e coletivistas pareciam insatisfatórias. Em uma avaliação geral sobre essas alternativas de transformação social, Marshall revela todo o seu ceticismo em relação às suas possibilidades de sucesso duradouro:

[...] Eu não duvido que os caminhos para onde eles nos levam possam ser, provavelmente, repletos de rosas por alguma distância. Mas estou convencido de que, tão logo o controle coletivo espalhar-se a ponto de estreitar consideravelmente o campo da livre-iniciativa, a pressão dos métodos burocráticos [...] irá danificar não somente as molas da riqueza material, como também muitas daquelas qualidades da natureza humana, cujo fortalecimento deveria ser a principal meta do esforço social (Marshall, [1907] (1966), p. 334).

Por essas razões, Marshall afirma: "Eu considero o movimento socialista não somente um perigo, mas o maior perigo no presente ao bem-estar humano" (Marshall apud Parsons, 1931a, p. 124).

\section{Melhorando a sociedade: Marshall e sua utopia social}

A despeito de rejeitar firmemente as alternativas coletivistas e socialistas, Marshall deixa claro que reprovava a adoção de uma atitude passiva em relação aos males de sua sociedade. Ele considerava o "[...] torpor moral que permite que nós, com nossos recursos e conhecimentos modernos, observemos com contentamento a destruição, em multidões de vidas humanas, de tudo que vale a pena ter [...]" (Marshall, [1920] (1982), p. 601) ainda mais nocivo do que a impaciência irresponsável desses reformadores. Segundo ele, “[...] não há nenhuma necessidade e, portanto, nenhuma justificativa moral para existência de pobreza lado a lado à enorme riqueza [...]" (Ibidem, p. 594) ${ }^{30}$.

Marshall acreditava ainda que para sanar as mais importantes mazelas ainda vigentes na sociedade seria essencial uma ação enérgica do Estado. Nesse sentido, apesar de criticar o peso dado a este nas propostas socialistas e coletivistas, ele certamente não pode ser considerado um adepto dogmático do laissez-faire. Na sua filosofia social, o Estado deveria estar "[...] em pé e atuando" (Marshall, [1907] (1966), p. 336) na busca do objetivo de melhorar as condições sociais $^{31}$

(30) Para Marshall (1890), as desigualdades existentes eram grandes demais e daria para manter o estímulo à iniciativa e empenho com ganhos bem menores: "O progresso econômico requer como condição livre responsabilidade individual, mas não a manutenção daqueles direitos de propriedade que acarretam desigualdades extremas de riqueza" (p. 282).

(31) Na seguinte passagem isso fica claro: "Nos dizem às vezes que todo mundo que se esforça com energia para promover o melhoramento social de um povo é socialista [...] caso acredite que muito deste trabalho pode ser desempenhado melhor pelo Estado do que pelo esforço individual. [...] Nesse sentido eu fui um socialista mesmo antes de saber qualquer coisa sobre economia; e foi inclusive o meu desejo de saber o que era 
O Estado deveria intervir diretamente nas questões da pobreza, da indigência e das péssimas condições de vida, de forma a eliminar aqueles elementos que ainda degradavam uma parcela dos homens de sua sociedade.

Embora atacasse a velha Lei dos Pobres, considerava essencial fornecer auxílio aos necessitados e, para tanto, propôs um complexo esquema de auxílio aos pobres, que envolveria o Estado e a sociedade civil (Reisman, 1987, p. 209). Todavia, essa seria apenas uma política emergencial, paliativa e de cunho paternalista para lidar com o problema da pobreza. Marshall defendeu outras políticas que tinham como objetivo romper o círculo vicioso no qual os trabalhadores pobres e os integrantes do Residuum encontravam-se presos.

O Estado deveria regulamentar (tornando obrigatória) e ofertar gratuitamente educação para as crianças, além de limitar o trabalho infantil e das mulheres. Adicionalmente, deveria fazer um planejamento urbano e controlar a densidade populacional (especialmente em Londres) inspecionando os cortiços e estabelecendo limites de habitantes por metro quadrado. Essa seria uma forma de melhorar as condições de habitação - que eram extremamente insalubres - e, consequentemente, a saúde dos trabalhadores pobres. Construir parques públicos e áreas de lazer abertos para todos e tornar a arte e a cultura acessíveis à população em geral eram igualmente consideradas missões fundamentais do Estado (Marshall, [1920] (1982), p. 597-600) e Marshall, [1907] 1966). No seu conjunto, essas medidas além de gerarem cidadãos mais saudáveis e responsáveis, teriam um grande impacto sobre a qualificação e produtividade dos trabalhadores, de seus filhos e dos indivíduos pertencentes ao Residuum. Com isso conseguiriam empregos menos exaustivos e desgastantes, salários melhores, o que, por sua vez, viabilizaria um melhoramento nas condições de habitação, saúde e cultura, elevando a sua qualidade de vida. O círculo vicioso da pobreza seria, assim, substituído por um círculo virtuoso de melhoramento moral e social.

Essas políticas seriam, sem dúvida, fundamentais para melhorar a situação degradada em que ainda vivia uma parcela significativa da população. No entanto, é importante notar que o caminho para a sociedade que almejava não deveria ser, no entender de Marshall, pavimentado apenas pelas mãos do Estado ${ }^{32}$. Muito pelo contrário, ele não desejava vê-lo ocupando espaços crescentes na vida econômica e social. $\mathrm{O}$ "[...] governo [deveria] se levantar para fazer aquele trabalho que é

possível de ser praticado em termos de reforma social pelo Estado e por outras agências que me levou a ler A. Smith, e Mill, Marx e Lassale há quarenta anos. Desde então eu venho me tornando crescentemente um socialista convicto nesse sentido da palavra" (Marshall, [1907], p. 334, ênfase adicionada). Groenewegen (1995, p. 592) caracteriza o 'socialismo' de Marshall como sendo um socialismo com 's' minúsculo.

(32) Como coloca Biagini (2006), para Marshall, a intervenção do Estado "[...] deveria ser encorajada somente como último recurso [...] as associações voluntárias e a sociedade civil arcavam com a principal responsabilidade pela remoção da desigualdade e do sofrimento" (p. 557). 
vital e que ninguém, a não ser o governo, pode fazer com eficiência." (Marshall, [1907] (1966), p. 335-336), mas deveria deixar a iniciativa privada fazer o resto, até para que fosse capaz de realizar com competência o que lhe era devido executar (Ibidem, p. 337).

A sua ação na produção, por exemplo, deveria ser bastante restrita. Marshall preferia confiar aos homens de negócios essa responsabilidade. Como foi visto, ele considerava os resultados em termos de caráter humano e principalmente em termos de inovações tecnológicas inferiores quando confiados ao Estado do que os engendrados por empresários enérgicos colocando em práticas os seus projetos. No seu entender, a maior responsabilidade pelo avanço econômico e social observado desde o advento do sistema de liberdade econômica coube a essa figura do empresário inovador. A sua criatividade, energia e disposição de assumir o risco e quebrar a rotina teriam garantido o dinamismo da economia e o aumento da prosperidade geral e eram esses elementos que gostaria de ver estimulados ${ }^{33}$.

Marshall acreditava ser fundamental que, concomitantemente às intervenções (pontuais) do Estado, ocorresse uma mudança generalizada nos valores da sociedade e, mais especificamente, naqueles dos homens de negócios. Ele entendia que o aperfeiçoamento moral dos indivíduos seria essencial para o progresso social e clamava por maiores doses de nobreza no agir econômico, denominado por ele de cavalheirismo econômico (economic chilvary). Só assim a sociedade poderia alcançar uma situação verdadeiramente desejável e feliz ${ }^{34}$.

Marshall faz um paralelo entre os cavalheiros da Idade Média, que defendiam os seus príncipes e lutavam nas Cruzadas, e o agir dos homens de negócios no mercado. Para ele, os cavalheiros medievais cometiam as violências muito maiores do que aquelas cometidas pelos capitalistas e, no entanto, eram admirados por seu comportamento 'nobre' e pelos princípios éticos que norteavam as suas condutas. Marshall clamava por cavalheirismo no agir econômico, postura que incluiria o espírito público, a vontade de realizar coisas nobres e difíceis pelo

(33) Shove (1942) argumenta que Marshall escreveu quando o capitalismo competitivo estava no seu auge. Ele teria revolucionado as técnicas industriais, as comunicações os transportes e, a partir de meados do século XIX, elevado a renda real da população e [...] tudo isso tinha sido conseguido através da iniciativa individual, da 'agitada energia' (restless energy) do homem de negócios rumando o seu próprio caminho e sem grande ajuda do governo [...]" (p. 317). E, diante disso, se pergunta: "Podemos ficar surpresos que, para ele [Marshall], a iniciativa individual, o 'audacioso' e 'livre' empreendimento do inovador era a coisa acima de todas as outras a ser cultivada e encorajada de forma a que o progresso pudesse continuar?” (Ibidem, p. 318).

(34) Como aponta Viner (1941): "As suas esperanças de melhoramento social se apoiavam na capacidade de indústria [industry], frugalidade, empreendimento, cooperação voluntária, e 'cavalheirismo econômico', de indivíduos esclarecidos e ele tinha confiança limitada, apesar de alguma, na possibilidade de melhoramento através de legislação coerciva ou por meio de atuação direta de empreendimentos governamentais na esfera econômica" (p. 226). Para uma interessante análise do cavalheirismo econômico em Marshall, ver Gerbier (2006). 
mero desafio de realizá-las, e uma valorização da riqueza mais pelo sucesso e pela liderança que atesta do que por si mesma (Marshall, [1907] (1966), p. 331).

Apresentando uma visão bastante idealizada do capitalista empreendedor, ele afirma que esse elemento nobre em alguma medida já existia nos negócios, e que aqueles que realmente trouxeram contribuições à indústria tinham esse perfil, ou seja, buscavam o sucesso nos negócios mais como uma forma de reconhecimento social do que de enriquecimento (Marshall, [1907] (1966), p. 331$332)^{35}$. No entanto, reconhecia que muitos homens de negócios não tinham essa descrição e que restavam muitos elementos pouco 'nobres' ou 'cavalheirescos' na vida econômica. Para corrigir essa situação, novamente a opinião pública tinha um papel importante a cumprir. Seria fundamental que ela passasse a diferenciar os bons e os maus homens de negócios, valorizando não a riqueza, mas acima de tudo a forma como esta foi obtida (Ibidem, p. 343). Essa mudança de valores traria muitos benefícios:

[...] caso as gerações vindouras procurassem e honrassem aquilo que é verdadeiramente cavalheiresco nos negócios modernos, o mundo cresceria rapidamente em riqueza material e em riqueza de caráter. Esforços nobres seriam evocados [...] Ganhar dinheiro por meios sórdidos não teria lugar nessa sociedade [...] (Ibidem).

O cavalheirismo econômico também demandaria maior envolvimento dos indivíduos em associações voluntárias que visavam à promoção do bem comum. Ele enxergava grande potencial nesse tipo de ação voluntária, que já era praticado em alguma medida na Inglaterra de sua época:

[...] esse país é capaz de ter comitês voluntários, constituídos por homens altamente treinados no setor privado, que fornecem conselhos gerais gratuitamente [...] e esse é, novamente, um tipo de cavalheirismo funcionando e que tem grande potencialidade para o bem [...] (Ibidem, p. 343-344).

Com o progresso em termos morais e intelectuais, os gastos, ou seja, os destinos dados à riqueza gerada, também iriam ser modificados. Apesar de

(35) Em outro ensaio, Marshall (1890) frisa que “[...] as motivações que induzem um homem de negócios a competir por riqueza não são geralmente tão sórdidas como o mundo em geral [...] tem tido a tendência a assumir" (p. 281). E adiciona: "[...] os homens de negócios têm uma natureza muito similar à dos homens da ciência, eles têm o mesmo 'instinto da busca', e muitos deles têm a capacidade de serem estimulados a empenhos grandes e mesmo entusiásticos através de emulações que não são sórdidas ou ignóbeis. Essa parte de sua natureza tem sido, entretanto, confundida e jogada à sombra por seu desejo de ganhar dinheiro [...]. A principal razão pela qual o cientista não liga muito para o dinheiro é que no trabalho científico ganhar dinheiro não é prova de excelência [...]. De outro lado, nos negócios o poder do homem de ganhar dinheiro, apesar de não ser um teste do valor real para o mundo do que ele fez, é, ainda assim, o melhor teste disponível [...]. Assim, todos os melhores homens de negócios querem obter dinheiro, mas muitos deles não ligam para ele em si mesmo; eles o querem principalmente como uma prova convincente para eles e para os outros de que eles tiveram sucesso" (Ibidem, p. 281-282). 
Marshall enfatizar que a parcela das rendas dos ingleses de sua época destinada a gastos sociais era muito maior que a de seus antepassados, ele ainda via grandes desperdícios na forma pela qual principalmente os homens ricos usavam suas riquezas. Boa parte desses gastos era efetuada para impressionar os outros e manter o prestígio de sua posição social, sem quase nenhum ganho em termos de bem-estar para esses indivíduos (Ibidem, p. 325).

Esse desperdício seria evitado caso a "[...] sociedade pudesse atribuir essa honra, posição e influência por meio de métodos menos cegos [....]" (Ibidem, p. 325) e dar valor a outras coisas mais louváveis, desestimulando os gastos 'inúteis'. Neste novo contexto, a “[d]espesa só para a exibição [...] seria considerada vulgar [...]" (Ibidem, p. 344) e os recursos assim liberados poderiam ser "[...] destinados a abrir para a massa da população novas possibilidades de uma vida mais elevada e de atividades artísticas e intelectuais maiores e mais variadas" (Ibidem, p. 325).

Com a alteração nos seus valores, a sociedade poderia optar também por reduzir a jornada de trabalho, mesmo que à custa de uma redução de riqueza, de forma que os trabalhadores não fossem embrutecidos por suas atividades diárias ${ }^{36}$. Para Marshall, não seria possível chegar a uma situação na qual todas as atividades manuais não qualificadas que não enobreceriam o homem fossem eliminadas, mas certamente dever-se-ia lutar para que a distribuição desse trabalho na sociedade ocorresse de modo que nenhum homem fosse sobrecarregado por ele:

Nossa geração reconhecerá [...] que algum trabalho não enobrecedor terá que ser executado. No entanto, irá buscar aplicar o conhecimento e os recursos materiais crescentes para confinar tal trabalho dentro de limites estreitos, e para extirpar todas as condições de vida que são em si mesmas degradantes." (Marshall, [1897] 1966, p. 311) ${ }^{37}$.

A sociedade vislumbrada por Marshall é bastante diferente da vigente em sua época. Nela "[...] o trabalho manual, levado a tal extremo que deixa pouca oportunidade para o livre crescimento da sua natureza mais elevada, estará ausente [...]" (Marshall, [1873] (1966), p. 118). E se a classe trabalhadora é constituída por homens massacrados por trabalho excessivo, "[...] nesta medida, a classe

(36) Marshall ([1920] 1982) frisa novamente a mudança de valores sociais: "[a] geração que está chegando está interessada no resgate do homem e, especialmente, da mulher, do trabalho excessivo [...]" (p. 578). E ele acreditava que a eliminação destas horas de trabalho poderia até ocorrer sem queda permanente no nível de riqueza, por conta do efeito que o aumento de qualidade de vida teria sobre a eficiência dos trabalhadores: "[...] a sua maior energia, inteligência e força de caráter permitiriam a eles fazer o mesmo que antes em menos tempo [...]" (Idem).

(37) “A questão não é se no final todos os homens serão iguais - isso eles certamente não serão - mas se o progresso não pode prosseguir vagarosa e constantemente até que a distinção oficial entre o trabalhador e o gentleman seja eliminada; até que, pelo menos no que tange à profissão, todo homem seja um gentleman. Eu entendo que é possível e que irá ocorrer" (Marshall, [1873] (1966), p. 102). 
trabalhadora terá sido abolida." (Idem, ênfase adicionada). Diferentemente do que ocorria em sua sociedade, esta seria "[...] uma condição na qual todas as energias e atividades dos homens serão integralmente desenvolvidas [...] (Ibidem, p. 118).

No entanto, é interessante enfatizar o ceticismo de Marshall em relação a soluções repentinas. A epígrafe que ele escolhe para os Princípios - "Natura non facit saltum" - representa bem a sua visão no que concerne às mudanças sociais. Estas demandariam tempo uma vez que, no seu entender, as condições de vida formariam, mas também eram formadas pelos homens e, portanto, precisariam acompanhar o ritmo moroso da modificação da natureza humana (Marshall [1897] 1966, p. 311). O que se demandava eram alterações persistentes e contínuas que ao final de um período de tempo produzissem as melhorias desejadas nas condições sociais e nos homens.

De qualquer forma, a visão de Marshall sobre as possibilidades futuras da sociedade não deixa de ser luminosa. Nesse sentido, ele não parece ser menos utópico do que os socialistas que tanto criticava. Só que no seu caso, o caminho para a sociedade melhor seria gradual, contínuo, voluntário e, em grande medida, espontâneo. Sem a necessidade de alterações radicais nas instituições sociais existentes chegar-se-ia a uma situação verdadeiramente justa e feliz:

Sob tais condições as pessoas iriam em geral ser tão bem nutridas e tão verdadeiramente educadas que a terra seria um lugar agradável de viver. Os salários seriam altos por hora, mas o trabalho não seria caro. $\mathrm{O}$ capital não estaria ansioso para emigrar dele, mesmo que pesados impostos fossem recolhidos para finalidades públicas [...]; e assim um verdadeiro socialismo, baseado em cavalheirismo, surgiria [...]. Socialismo Nacional desta espécie pode ser cheio de individualidade e elasticidade [...] (Marshall, [1907] (1966), p. 345-346) ${ }^{38}$.

\section{Considerações finais}

Marshall, apesar de apreciar sobremaneira o capitalismo, não era cego ao sofrimento social existente em sua época, principalmente àquele relacionado à pobreza e à indigência. Ele defendeu intervenções pontuais (apesar de cruciais) do Estado, além de melhoramentos nos valores dos indivíduos e consequente crescimento do envolvimento da sociedade civil na resolução desses problemas.

A sua busca parece ser por um equilíbrio entre o imperativo de se intervir por meio do Estado para melhorar as condições vigentes e a necessidade de manter um largo espaço para a iniciativa e a energia individual - fontes do progresso econômico e social. No entanto, é interessante notar que essa tensão tende a se

(38) Tullberg (2006, p. 518) sugere que na utopia de Marshall as indústrias seriam organizadas segundo o princípio cooperativo, mas passagens como a citada revelam que continuaria a existir a relação assalariada, caracterizada pela divisão entre o capital e o trabalho. 
diluir naturalmente com a continuidade do melhoramento humano e com o aumento do cavalheirismo nas condutas econômicas. Na medida em que os indivíduos passarem a considerar sua responsabilidade colaborar para a solução dos problemas sociais, a própria necessidade de intervenção do Estado tornar-se-á, paulatinamente, menor ${ }^{39}$. O caminho para uma sociedade melhor não envolveria, assim grandes rupturas, pelo contrário, dar-se-ia de forma gradual, lenta e crescentemente voluntária.

De fato, Marshall vai somente até determinado ponto no que concerne à modificação do sistema vigente. Está certo que ele gostaria de ver uma melhoria na distribuição de renda, um aumento de gastos sociais, e estava disposto a lançar mão de imposto de renda progressivo, da educação pública, do planejamento urbano, e outras medidas para atingir esses fins. No entanto, não defendeu o fim da competição no mercado ou da propriedade privada, e rejeitou frontalmente as alternativas de gestão coletiva da produção ${ }^{40}$.

Mesmo quando apresenta a situação (utópica) do futuro, na qual o cavalheirismo econômico já teria modificado a ação econômica dos homens, Marshall se refere a uma estrutura social bastante similar àquela prevalecente em sua época. Nessa sociedade melhor, os trabalhadores seriam educados, bem nutridos e ganhariam bons salários, e os capitalistas estariam felizes em empregar seu capital. $\mathrm{O}$ trabalho com efeitos degradantes sobre a natureza humana seria eliminado (e, neste sentido específico, a classe trabalhadora seria abolida), mas não a relação assalariada ${ }^{41}$.

Ao contrário de seu antecessor J. S. Mill, que considerava o trabalho assalariado uma condição indigna para o homem não importando quão altos fossem os salários, Marshall não parecia ter nenhuma objeção importante contra essa instituição central do capitalismo. Nesse sentido, Joan Robinson parece ter

(39) Vários comentadores chamam atenção para esse ponto. Parsons (1931a) afirma: "[...] Ao mesmo tempo que, em alguma medida, o avanço moral facilitava uma extensão das funções do Estado, em medida ainda maior tenderia a torná-la desnecessária e a fazer com que o sistema de liberdade econômica pudesse funcionar com um mínimo de regulação." (p. 125). No mesmo sentido, Whitaker (1977) coloca: "Se nenhum indivíduo se sente em paz a não ser 'dando seu tempo e sua substância' para diminuir o número de excluídos da sociedade, existe muito menos necessidade de o governo exercer-se no assunto" (p. 177). Ver também Reisman (1990, p. 14).

(40) Como coloca Viner (1941): "Enquanto reconhecia o problema da pobreza como importante, ele nunca revelou qualquer dúvida de que ele poderia ser substancialmente resolvido dentro dos limites da democracia parlamentar britânica e de uma economia de livre-iniciativa" (p. 227). Schumpeter (1941) afirma no mesmo sentido: "[...] Ele [Marshall] aceitava as instituições que o circundavam, a propriedade privada das firmas e a família [family home] em particular, e não apresentou nenhuma dúvida sobre sua vitalidade ou a vitalidade da civilização que cresceu em torno delas [...]" (p. 244).

(41) Groenewegen (1995) afirma que "[d]e muitas formas ele [Marshall] substituiu o socialismo pelo cavalheirismo econômico [...]" (p. 608). E, de fato, apesar de Marshall utilizar o termo Socialismo Nacional para descrever a situação (ideal) que poderia ser atingida pela sociedade, a sua utopia parece situar-se bem mais próxima do campo liberal do que do socialista. 
razão quando afirma que ele tenta apresentar esse sistema sob uma luz agradável. A sua utopia social não envolve nenhuma mudança substantiva nas relações sociais - o que é apresentado é apenas um capitalismo 'civilizado' e melhorado de forma a produzir menos injustiças sociais e a oferecer uma condição de vida melhor aos trabalhadores. Viner (1941) capta com perfeição a natureza das mensagens vitorianas de Marshall quando afirma:

[...] elas tipicamente terminavam com dupla mensagem de garantia, de um lado, sobre a continuidade no futuro de todas as bem estabelecidas instituições da era vitoriana, e de promessa, por outro lado, de melhoramento contínuo das condições sociais da humanidade [...] (p. 235).

\section{Referências bibliográficas}

BIAGINI, E. New liberalism. In: RAFFAELLI, Tiziano; BECATTINI, Giacomo; DARDI, Marco (Ed.). The Elgar Companion to Alfred Marshall. Cheltenham, UK: Edward Elgar, 2006.

CALDARI, K. Alfred Marshall's idea of progress and sustainable development. Journal of the History of Economic Thought, v. 26 n. 4, p. 519-536, 2004.

COATS, A. W. Marshall and ethics. In: McWILLIAMS TULLBERG, R. (Ed.). Alfred Marshall in retrospect. Vermont: Edward Elgar, 1990.

COLLINI, S. et al. That noble science of politics: a study in nineteenth-century intellectual history. Cambridge: Cambridge University Press, 1983.

GERBIER, B. Economic Chivalry. In: RAFFAELLI, Tiziano; BECATTINI, Giacomo; DARDI, Marco (Ed.). The Elgar Companion to Alfred Marshall. Cheltenham, UK: Edward Elgar, 2006.

GROENEWEGEN, P. A soaring eagle: Alfred Marshall 1842-1924. Aldershot: Edward Elgar, 1995.

KEYNES, J. M. [1925]. Alfred Marshall, 1842-1924. In: PIGOU, A. C. (Ed.). Memorials of Alfred Marshall. New York: Augustus M. Kelley, 1966.

KEYNES, J. M. [1926]. O fim do laissez-faire” em John Maynard Keynes: Economia. Organização Tamás Szmerecsanyi. São Paulo: Editora Ática, 1984.

MALONEY, J. Marshall and business. In: McWILLIAMS TULLBERG, R. (Ed.). Alfred Marshall in retrospect. Vermont: Edward Elgar, 1990.

MARSHALL, A. [1873]. The future of the working classes. In: PIGOU, A. C. (Ed.). Memorials of Alfred Marshall. New York: Augustus M. Kelley, 1966.

[1885]. The present position of Economics. In: PIGOU, A. C. (Ed.). Memorials

of Alfred Marshall. New York: Augustus M. Kelley, 1966.

[1890]. Some aspects of competition. In: PIGOU, A. C. (Ed.). Memorials of Alfred Marshall. New York: Augustus M. Kelley, 1966. 
MARSHALL, A. [1907]. The social possibilities of economic chilvary. In: PIGOU, A. C. (Ed.). Memorials of Alfred Marshall. New York: Augustus M. Kelley, 1966.

[1920]. Principles of economics. Pennsylvania: Porcupine Press, 1982.

PARSONS, T. Wants and activities in Marshall. Quarterly Journal of Economics, n. 46, 1931a.

. Economics and sociology: Marshall in relation to the thought of his time. Quarterly Journal of Economics, n. 46, p. 316-347, 1931 b.

PESCIARELLI, E. Entrepreneurship and profits. In: RAFFAELLI, Tiziano; BECATTINI, Giacomo; DARDI, Marco (Ed.). The Elgar Companion to Alfred Marshall. Cheltenham, UK: Edward Elgar, 2006.

RAFFAELLI, T. Character and capabilities. In: RAFFAELLI, Tiziano; BECATTINI, Giacomo; DARDI, Marco (Ed.). The Elgar Companion to Alfred Marshall. Cheltenham, UK: Edward Elgar, 2006.

REISMAN, D. Alfred Marshall: progress and politics. Macmillan Press, 1987.

. Alfred Marshall's mission. MacMillan Press, 1990.

ROBINSON, J. Marx, Marshall and Keynes - Three views of capitalism. In:

Collected Economic Papers of Joan Robinson. Oxford: Basil Backwell, 1964. v. 2.

SCHUMPETER, J. A. Alfred Marshall's principles: a semi-centennial appraisal. The American Economic Review, v. 31, n. 2, p. 236-248, 1941.

SHOVE, G. F. The place of Marshall's principles in the development of economic theory. The Economic Journal, v. 52, n. 208, p. 294-329, 1942.

TULlBERG, R. Socialism. RAFFAELLI, Tiziano; BECATTINI, Giacomo; DARDI, Marco (Ed.). The Elgar Companion to Alfred Marshall. Cheltenham, UK: Edward Elgar, 2006.

VINER, J. Marshall's economics in relation to the man and to his times. The American Economic Review, v. 31, n. 2, 1941.

WHITAKER, J. K. Some neglected aspects of Alfred Marshall's economic and social thought. History of Political Economy (HOPE), v. 9, n. 2, 1977. 